\title{
Modified reservoir quality indicator methodology for improved hydraulic flow unit characterization using the normalized pore throat methodology (Niger Delta field as case study)
}

\author{
Haruna M. Onuh ${ }^{1} \cdot$ O. Ogbe David ${ }^{1,2} \cdot$ Charles Yunusa Onuh $^{3}$
}

Received: 5 May 2016/Accepted: 24 October 2016/Published online: 15 November 2016

(c) The Author(s) 2016. This article is published with open access at Springerlink.com

\begin{abstract}
The detailed characterization of complex reservoir units, typical of the thin-bedded canyon turbidites system within the clastic environment is essential for accurate reservoir modelling. The sedimentary architecture usually overprinted by late diagenesis results in the intrinsic complexities which poses major problems in modelling these systems. Although the average permeabilities exhibited by most clastic reservoirs is relatively high, the low permeabilities of the component shale strata results in low sweep efficiency and transmissibilities, and may form effective flow baffles. Recent advances in petrophysical modelling and formation evaluation studies demonstrate the applicability of normalized pore throat radius $\overline{R_{\text {tot }}}$ methodology for improved reservoir characterization and production optimization in challenging systems. This paper presents a modification of the reservoir quality indicator (RQI) methodology for hydraulic flow unit characterization using the normalized pore throat concept. Result of the analysis for the various genetic reservoir units demonstrates an improvement with a correlation coefficient of $78 \%$ for the proposed modified RQI over $31 \%$ for the existing RQI method in defining the unit slope line for the Channel Storey Axis unit. In addition, regression analysis between the irreducible water saturation from mercury injection capillary pressures and FZI depicts a higher correlation coefficient of $76 \%$ for the modified RQI over $64 \%$ for the existing method. The
\end{abstract}

Haruna M. Onuh

onuhharuna@yahoo.com

1 African University of Science and Technology (AUST), Km 10, Airport Road, Abuja, Nigeria

2 Flowgrids Ltd, Port Harcourt, Rivers State, Nigeria

3 Covenant University, Ota, Nigeria higher correlation coefficient indicates an improved efficacy of the proposed model for hydraulic flow zone characterization. The efficacy of the proposed methodology was also validated with a numerical flow simulation model. This demonstrates improved efficient for reservoir characterization studies.

Keywords Normalized pore throat radius $\cdot$ Reservoir quality index · Flow zone indicators · Niger Delta . Flow simulation

\section{Introduction}

With the quest for hydrocarbon prospects in frontier deep water settings characterized by complex rock fabric, detailed reservoir characterization is essential for accurate field management and production optimization. The presence of multi-pore architecture within such depositional environment makes their description from petrophysics very complex. Numerous models have been reported in the literature for permeability and flow units characterization utilizing various parameters for improved petrophysical evaluation.

Onuh et al. (2015a, b) presented a genetic reservoir unit (lithofacies association)-based normalized pore throat $\overline{R_{\text {tot }}}$ approach for characterizing the complex reservoir pore systems to provide improved methodology for petrophysical evaluation for the clastic reservoirs with Niger Delta as field case study. The normalized pore throat method captures the relative contribution of a pore system as a complex interplay of porosity, pore connectivity, grain packing, and grain size rather than porosity alone as shown in Eq. (1).

$\overline{R_{\mathrm{tot}}}=\phi_{i} \sum_{i} S_{w i} R_{p i}=\phi \cdot 10^{\sum_{i} \Delta S_{w i} \cdot \log _{10}\left(R_{p i}\right)}$ 
where $\phi_{i}(\mathrm{v} / \mathrm{v})$, contribution of the total porosity accessible at the $i$ th pressure step; $S_{w i}(\mathrm{v} / \mathrm{v})$, incremental pore volume at the $i$ th pressure step; $R_{p i}(\mu \mathrm{m})$, pore throat radius at every $i$ th pressure step.

The methodology provides improved prediction of absolute permeability in uncored reservoir intervals and their implications in hydrocarbon fluid transmissibility, reservoir quality, and hydraulic flow unit definition; necessary for developing effective reservoir characterization programs.

Several authors have established various definitions of hydraulic flow units, which are the resultant of the depositional environment and diagenetic processes. The subdivision of a reservoir into flow units provides a practical means for reservoir zonation that makes use of both geological and petrophysical data representing heterogeneity observed at several scales. According to Tiab (2000), a hydraulic flow unit is a continuous body over a specific reservoir volume that practically possesses consistent petrophysical and fluid properties, which uniquely characterize its static and dynamic communication with the wellbore. There are three industry-recognized methods for calculating flow potential in clastic rocks; reservoir quality index (RQI), Winland R35 method, and Pittman methods.

This paper focuses on the modification of the reservoir quality index (RQI) approach for hydraulic flow unit characterization using the normalized pore throat method. A case study from the challenging deep water depositional environment with thin-bedded turbidite sequence is present which demonstrates the efficacy of the proposed methodology for improved reservoir characterization studies.

\section{The reservoir quality indicator $(\mathrm{RQI})$ concept}

The reservoir quality indicator (RQI) method for classifying reservoir data into distinct hydraulic flow units (HFU) with specific FZI was introduced by Amaefule et al. (1993). They presented a reliable and robust methodology for enhanced reservoir description which also captures the pore-body/throat attributes of a given reservoir system. The methodology was based on a modified Kozeny (1927) and Carmen (1937) relationship (Eq. 2). They expressed the permeability $(K)$ in terms of effective porosity $\left(\varphi_{\mathrm{e}}\right)$, shape factor $\left(F_{\mathrm{s}}\right)$, tortuosity $(\tau)$, and surface area per unit grain volume $\left(S_{\mathrm{gv}}\right)$ as follows:

$K=1014 \frac{\varphi_{\mathrm{e}}^{3}}{\left(1-\varphi_{\mathrm{e}}\right)^{2}}\left(\frac{1}{F_{\mathrm{s}} \tau^{2} S_{\mathrm{gv}}^{2}}\right)$

The parameters $F_{\mathrm{s}}$ and $\tau$ were grouped into a term called Kozeny constant. However, this term actually varies among hydraulic units, although it is constant within a given rock unit.

To address the variability of the Kozeny "constant", Amaefule rearranged Eq. (2) by dividing both sides by porosity and taking the square root of both sides:

$\sqrt{\frac{K}{\varphi_{\mathrm{e}}}}=\left(\frac{\varphi_{\mathrm{e}}}{1-\varphi_{\mathrm{e}}}\right)\left[\frac{1}{\sqrt{F_{\mathrm{s}}} \tau S_{\mathrm{gv}}}\right]$

Then, the reservoir quality index (RQI), pore volume-tograin ratio $\left(\varphi_{z}\right)$, and flow zone indicator (FZI) were introduced:

$\mathrm{RQI}=0.0314 \sqrt{\frac{K}{\varphi_{\mathrm{e}}}}$

$\varphi_{z}=\frac{\varphi_{\mathrm{e}}}{1-\varphi_{\mathrm{e}}}$

$\mathrm{FZI}=\frac{1}{\sqrt{F_{\mathrm{s}}} \tau S_{\mathrm{gv}}}=\frac{\mathrm{RQI}}{\varphi_{z}}$

Finally, substituting Eqs. (4), (5), and (6) into (3) and taking logarithm of both sides results in:

$\log \mathrm{RQI}=\log \varphi_{z}+\log \mathrm{FZI}$

As expressed in Eq. (6), the flow zone indicator FZI relates parameters as shape factor, tortuosity, and surface area per unit grain volume (all controlled by mineralogy and texture of the rock) to the ratio of permeability and effective porosity. This demonstrates an improved permeability modelling as a function of porosity. Thus, poorly sorted, fine-grained sands as well as rocks with high clay content typically exhibit high surface area, high shape factor, and tortuosity and hence, low FZI values. In contrast, rock samples composed of coarse grained and well-sorted grains have lower surface areas, lower shape factor, and tortuosity and consequently, higher FZI values.

\section{Integrating the $\overline{R_{\text {tot }}}$ with the $\mathrm{RQI}$ concept}

Onuh et al. (2015a, b) defined the relationship for pseudo averages of normalized pore throat radius as: $R_{\mathrm{tot}}=\overline{R_{\mathrm{tot}}} \varphi_{n}$; where $\overline{R_{\mathrm{tot}}}$, genetic units averages of pore throat radius for the various depositional environments within the Niger Delta system; $\varphi_{n}=0.3\left(\frac{1-\varphi}{\varphi}\right)$.

Substituting for $R_{\mathrm{tot}}$ in the RQI formulation (Eq. 4) results in:

$$
\begin{aligned}
\mathrm{RQI} & =0.0314 \sqrt{\frac{K}{R_{\mathrm{tot}}}} \\
\varphi_{z} & =\frac{\varphi_{\mathrm{e}}}{1-\varphi_{\mathrm{e}}}
\end{aligned}
$$


The plot of the logarithm of RQI versus the logarithm of $\varphi_{z}$ rearranges the porosity-permeability relationship and provides trends for various rock units with similar depositional/diagenetic imprints. Then, samples that lie on the same line have similar hydraulic behaviour, and thereby, similar fluid-flow characteristics. These trends can be fitted with parallel straight lines with unit slope whose intercept at $\varphi_{z}=1$ defines the FZI of each distinctive hydraulic unit.

\section{Case study of the clastic turbidite reservoirs}

\section{Introduction}

The case study encompasses the Niger Delta Deep Water turbidites system composed of submarine fan models which include the: amalgamated channels, isolated channel complex, sinuous channels, channel sand complexes, and levee/overbank deposits. Detailed laboratory core analysis and description for lithofacies definition, understanding the environment of deposition, and petrographic studies depict the presence of four key facies association within the system (Table 1). These are the mud-rich thin beds (MRTB), inter-channel thin beds (ICTB), Channel Storey Margin (CSM), and the Channel Storey Axis (CSA). Figures 1 and 2 present the petrophysical data log view showing core images and routine core analysis dataset, which depicts four major genetic reservoir units classification within the system. Gamma ray and deep resistivity signatures denote the environment as a low-resistive and low-contrast pay zone. NMR $T_{1}$ and $T_{2}$ spectrum confirms the zones as highly prolific with good reservoir and fluid properties. Special as well as routine core analysis dataset were obtained from the interval: X,226-X,567 ft MD.

Figure 3 demonstrates the classical porosity-permeability plot using dataset from the case study, indicating varying permeabilities at a given porosity which is typical of heterogeneous clastic reservoirs within the Tertiary Niger Delta system. Four distinct hydraulic units were

Table 1 Genetic Units Classification for the Turbidite/Deep Water Environment developed for the study

\begin{tabular}{|c|c|c|}
\hline Generalized classification & Units & Genetic reservoir units \\
\hline \multirow{3}{*}{$\begin{array}{l}\text { Amalgamated channel } \\
\text { fill Sandstone }\end{array}$} & 1 & Channel lag \\
\hline & & Channel Storey Axis (CSA) \\
\hline & 2 & Channel Storey Margin (CSM) \\
\hline \multirow{2}{*}{$\begin{array}{l}\text { Isolated and sinuous channel } \\
\text { Complexes }\end{array}$} & 3 & Inter-channel thin beds (ICTB) \\
\hline & & Mud-rich thin beds (MRTB) \\
\hline \multirow[t]{2}{*}{ Levee/overbank/mudstone } & 4 & Levees/overbank \\
\hline & & Marine mudstone \\
\hline
\end{tabular}

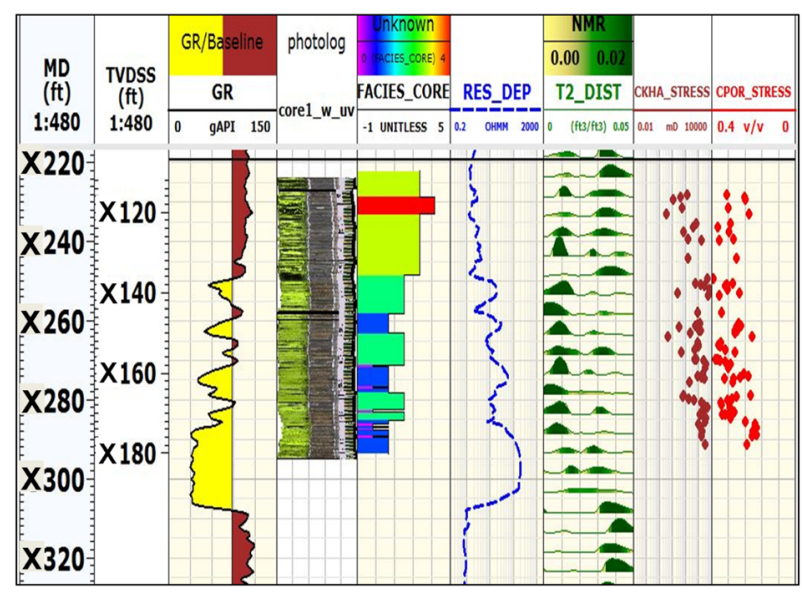

Fig. 1 PDL view for Zone 1 (deep water-Niger Delta) indicating the cored interval, complex turbiditic sequence of the submarine canyons and the facies association

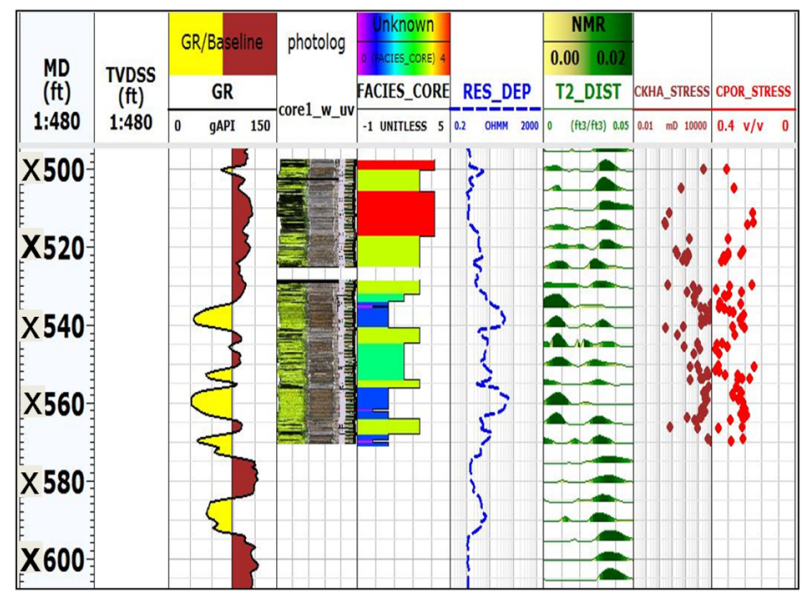

Fig. 2 PDL view for Zone 2 (deep water-Niger Delta) indicating the cored interval, complex turbiditic sequence of the submarine canyons and the facies association

established within the cored interval using both RQI methodologies.

The mercury injection capillary pressure (MICP) data presented in Fig. 4 demonstrate the existence of a distinctive profile of capillary pressure versus saturation for each of the four (4) genetic reservoir units. The following subsections present the applicability of the proposed methodology for permeability modelling and hydraulic flow unitization. In addition, the implication of the proposed methodology for flow simulation is also presented.

\section{Permeability modelling using the $\overline{R_{\mathrm{tot}}}$ methodology}

The efficacy of the proposed $\overline{R_{\text {tot }}}$ concept was validated for permeability modelling using the clastic dataset. Figure 5 presents the dataset obtained from the case study employed for this work. These include well logs: caliper, gamma ray, 


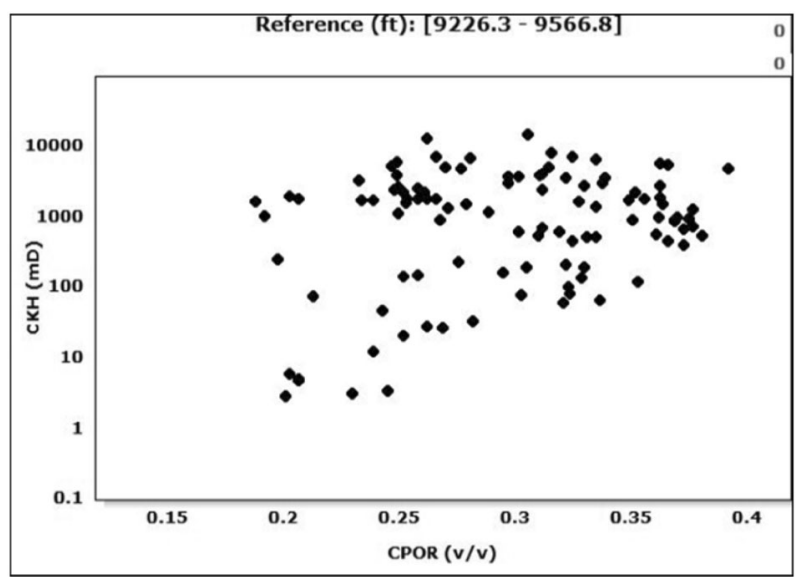

Fig. 3 Plot of permeability versus porosity for all samples; the nonlinear relationship results in very low correlation coefficient which is evident in complex shaley sandstone

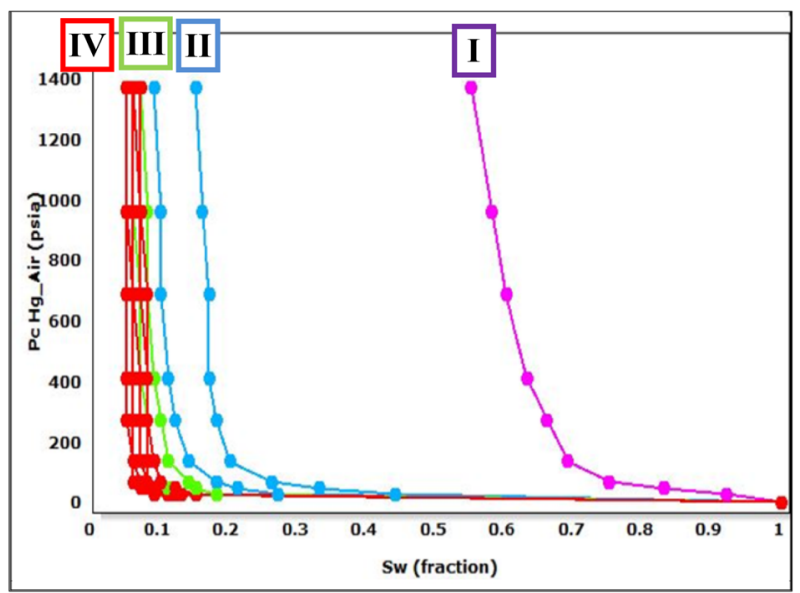

Fig. 4 Plot of capillary pressure versus wetting phase saturation indicating the four (4) distinct genetic units with increasing macropores from rock unit $I-I V$, and decreasing reservoir quality from rock unit $I V-I$

bulk density, neutron, resistivities, and NMR $T_{2}$ distribution; detailed geologic core description, stress-corrected porosities, and air permeabilities were available from routine core analysis. Seventy-five measured core analysis dataset covering two (2) prolific canyon reservoirs were obtained for validating the predicted permeabilities. The measured core permeabilities were analysed using nitrogen gas under a sleeve pressure of 400 psig permeameter and was corrected for the Klinkenberg effects. The predicted permeabilities were also compared to NMR-based correlations after the Schlumberger Research Doll (SDR) and Coates methodologies. Track 5 of Fig. 5 presents a plot of corrected core permeabilities with reference to the predicted from the proposed $\overline{R_{\text {tot }}}$, SDR and Coates models. The proposed approach demonstrates good correlation over the existing methodologies with a correlation coefficient of 0.987 and RMSE of 0.092 .

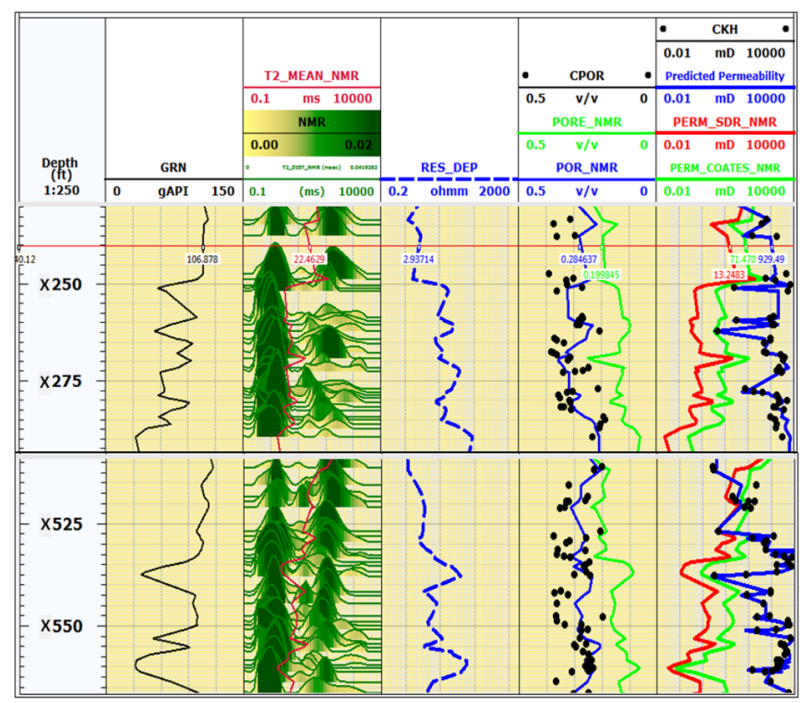

Fig. 5 PDL view of two hydrocarbon bearing zones within the lowcontrast and low-resistive thin-bedded turbidites. Track 5 presents a comparison of various permeability models indicating a good correlation between the proposed model and core derived permeabilities using 75 samples

\section{Reservoir zonation using the $\overline{R_{\mathrm{tot}}}$-based modified RQI methodology}

The modified RQI concept based on a combination of $\overline{R_{\text {tot }}}$ and permeability data demonstrates efficacy for hydraulic flow unit delineation. A simple summation and normalization of the modified RQI is sufficient for transforming rock-type-based reservoir zonation into petrophysicalbased flow units for input into a numerical flow simulator that honours the foot-by-foot characteristics at the wellbore. In such a plot, consistent zones are characterized by straight lines with the slope of the line indicating the overall reservoir quality within a particular depth interval. The lower the slope of the normalized modified RQI lines delineating each zone, the better the reservoir.

The equation used for calculating the Normalized Cumulative Modified RQI (NCMRQI), in this paper, is as follows:

$\mathrm{NCMRQI}=\frac{\sum_{x=1}^{i} \sqrt{\frac{K_{i}}{R_{\mathrm{toti}}}}}{\sum_{x=1}^{n} \sqrt{\frac{K_{i}}{R_{\mathrm{toti} i}}}}$

where $n$, total number of data; $i$, number of individual data points.

A plot of the NCMRQI versus depth demonstrates a possibility for delineating the reservoir into several zones by observing changes in the slope. Figures 6,7 , and 8 depict reservoir zones characterized by straight lines with changing slope indicating the overall reservoir quality within a particular depth interval. The straight lines shows similar slope for respective facies unit association as 


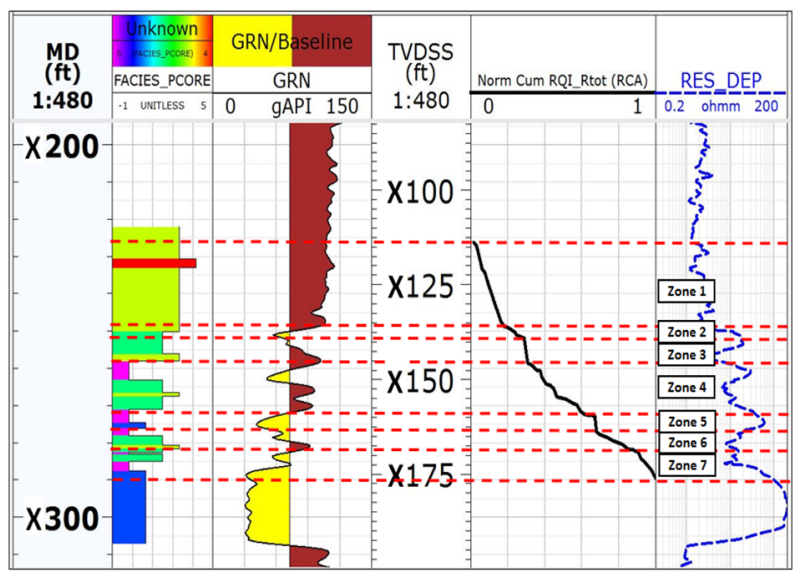

Fig. 6 PDL view for Zone 1 (deep water-Niger Delta). Track 3 presents the Normalized Modified RQI gradient for flow zones delineation. This presents good correlation between geologic facies and petrophysical units definition

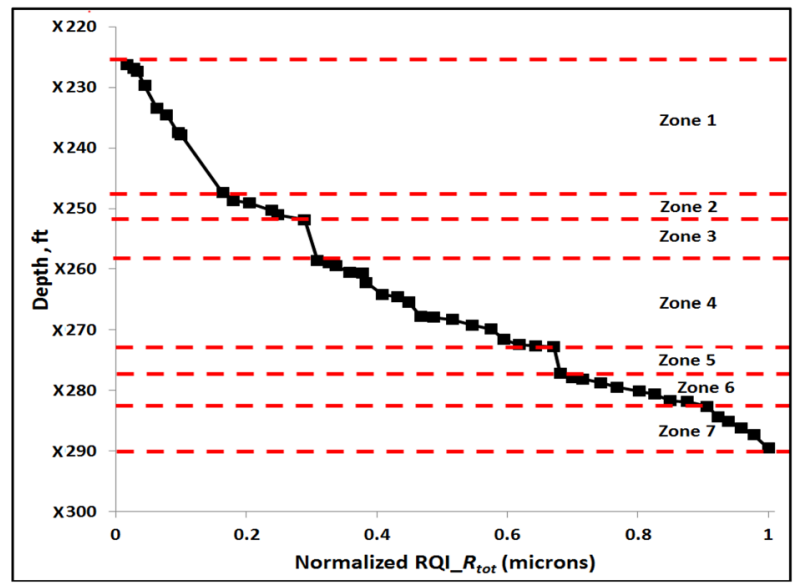

Fig. 7 Normalized Cumulative Modified RQI gradient in the cored section indicating seven reservoir flow units

depicted in Fig. 8, indicating consistency between the geologic rock classification and petrophysical units.

The RQI method and the modified RQI approach were analysed using dataset from the case study. Figures 9 and Fig. 10 present the efficacy of both methodologies for hydraulic flow unitization. FZI values ranged from 1.5 to 50 within the diagenetic sequence.

In addition, critical evaluation of individual genetic reservoir units for hydraulic flow unitization demonstrates an improvement in correlation coefficient as presented in Figs. 11 and 12 for the Channel Storey Axis unit. This shows a correlation coefficient of $78 \%$ (Fig. 12) from the proposed method over $31 \%$ (Fig. 11) for the existing RQI method after Ameafule et al.

Furthermore, Figs. 13 and 14 present plots of irreducible water saturation versus corresponding FZI values from ten (10) mercury injection capillary pressure samples obtained

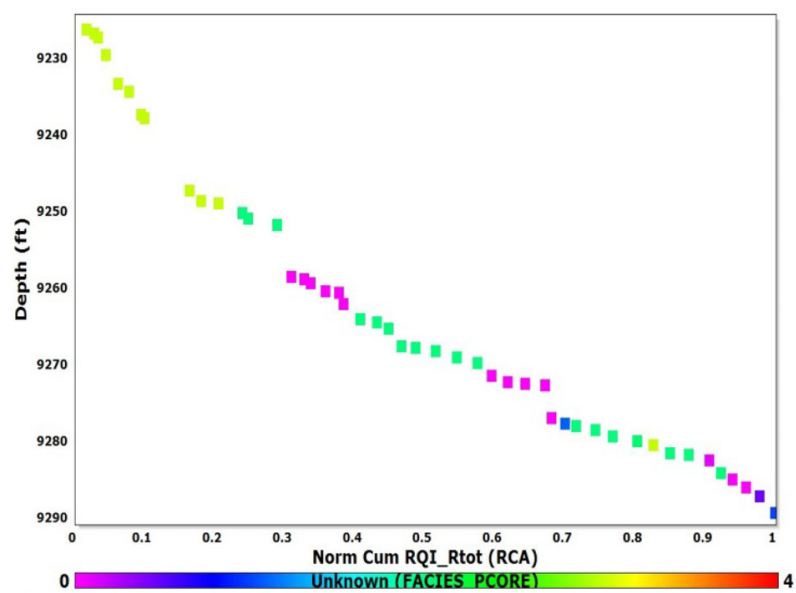

Fig. 8 Facies biased Normalized Cumulative Modified RQI versus depth within the cored section. This shows four units which bears correlation with the rock-type-based reservoir zonation and petrophysical-based flow units

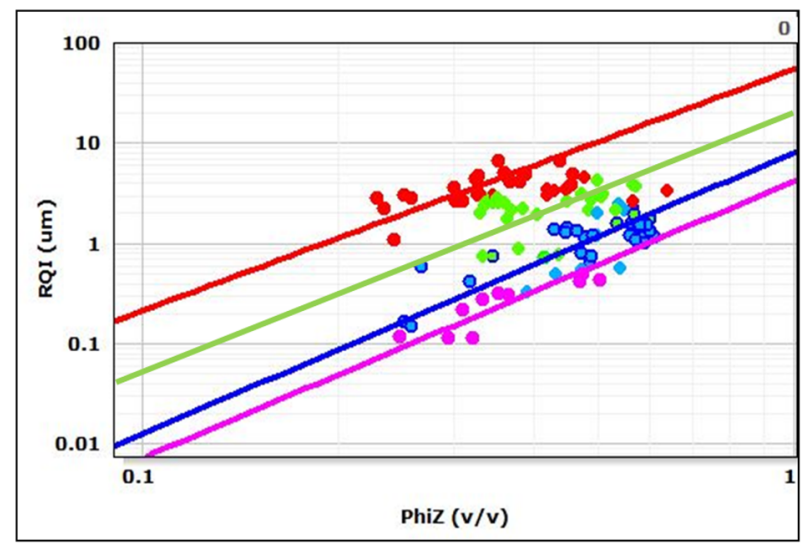

Fig. 9 Log-log plot of RQI (after Ameafule et al.) versus $\phi_{z}$ for all samples, indicating their average FZI per unit as obtained from the intercept of each straight line at $\phi_{z}=1$

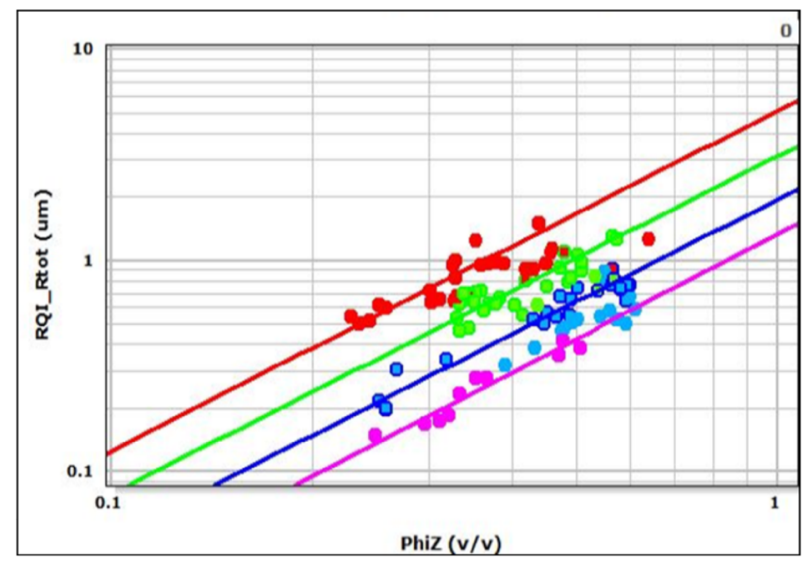

Fig. 10 Log-log plot of RQI_ $\overline{R_{\text {tot }}}$ (proposed model) versus $\phi_{z}$ for all samples, indicating their average FZI per unit as obtained from the intercept of each straight line at $\phi_{z}=1$ 


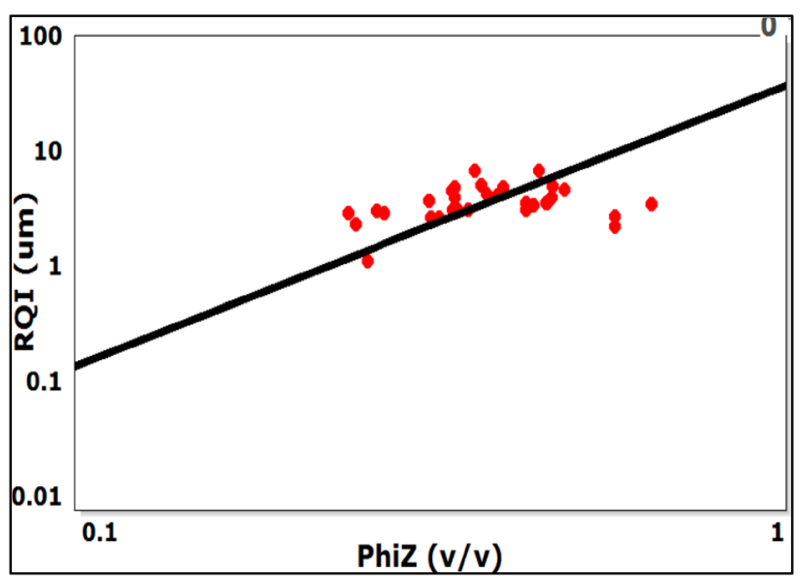

Fig. $11 \mathrm{Log}-\log$ plot of $R Q I$ versus $\phi_{\mathrm{z}}$ indicating $R^{2}$ of $31 \%$. For the Channel Storey Axis unit with a large scatter along the unit 1 slope line

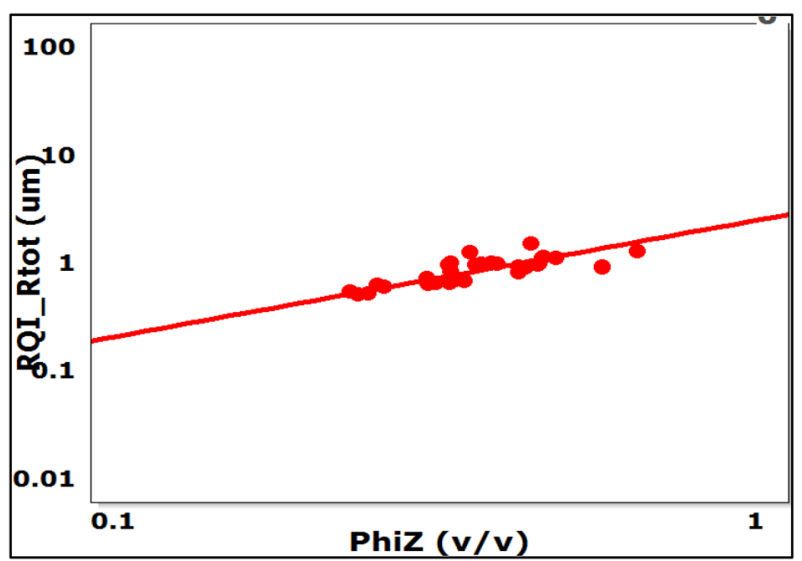

Fig. $12 \mathrm{Log}-\log$ plot of $R Q I_{-} \overline{R_{\mathrm{tot}}}$ versus $\phi_{\mathrm{z}}$ indicating improved $R^{2}$ of $78 \%$ for the modified RQI over $31 \%$ for the Channel Storey Axis unit. This depicts the efficacy of the proposed model for hydraulic flow zonation

from the study area. It is expected that higher FZI values correspond to larger pore throats (diagenetic/textural fabric) and subsequently lower irreducible water saturation and vice versa as evident in the plots. The proposed modified RQI demonstrates an improved correlation between irreducible water saturation and FZI. The higher correlation coefficient of $76 \%$ for the modified RQI (Fig. 14) over 64\% (Fig. 13) from the existing method indicates an improved efficacy of the proposed model for hydraulic flow zone characterization.

\section{Implication of the $\overline{R_{\mathrm{tot}}}$-based modified RQI methodology in 3D simulation studies}

Furthermore, a 3D reservoir model was built to validate the applicability of the proposed modified RQI method beyond well-centric view in 3D scale for field performance studies.

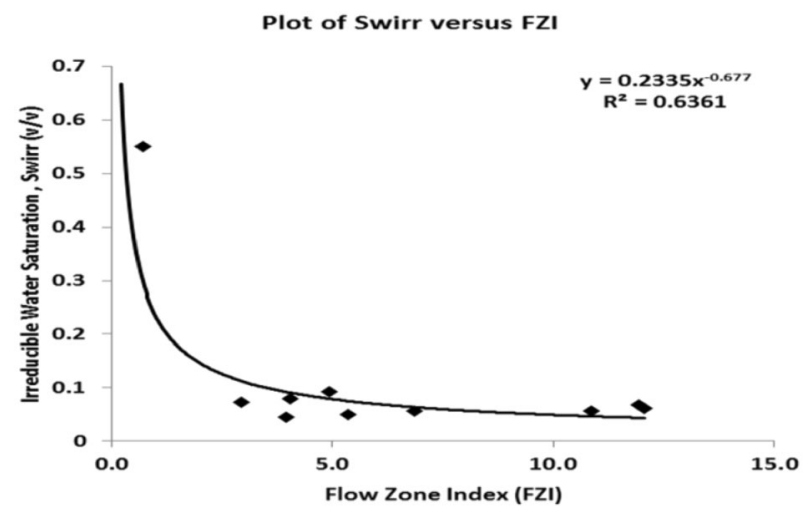

Fig. 13 Plot of irreducible water saturation versus FZI (after Ameafule et al.) for all samples. Higher FZI's corresponds to rock units with megapores and lower irreducible saturation

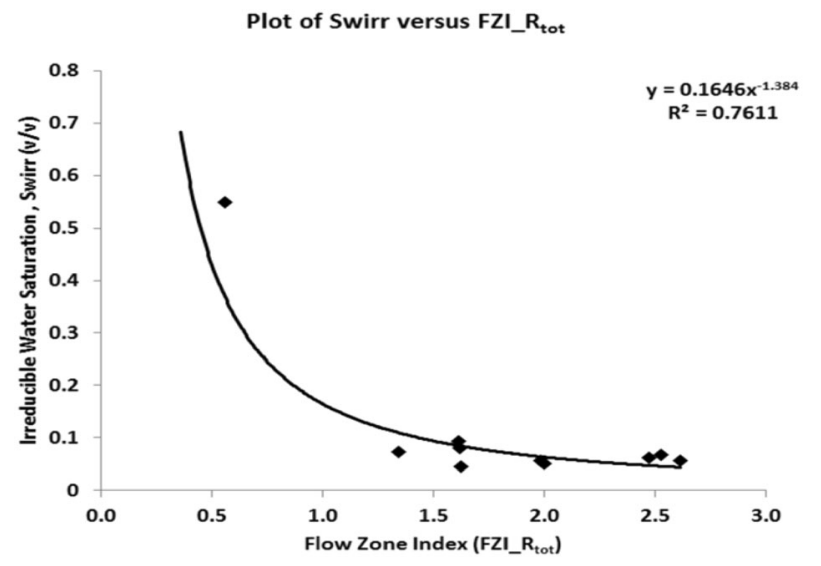

Fig. 14 Plot of irreducible water saturation versus FZI $\overline{R_{\text {tot }}}$ (proposed modified RQI) for all samples. Higher FZI's correspond to rock units with megapores and lower irreducible water saturation

The case study is built from dataset obtained from the Tertiary Niger Delta Deep Water depositional belt. A total of 14 wells (seven deviated, two sidetracks, and five horizontal) were drilled in the field. The reservoir is a black oil system with API gravity of $29^{\circ}$. Table 2 presents the reservoir rock and fluid properties. An estimated base case STOIIP of 201 MMSTB and GIIP of 4.6 BSCF was established from detailed geological reservoir characterization study. The field has produced approximately 84 MMSTB, achieving $42 \%$ field wide recovery. Production peaked at a 28.7 MBOPD (2001) with average water cut at approximately $80 \%$.

The structural interpretation depicts the subsurface reservoir as a fault-assisted closure within the deep water turbiditic environment. Table 3 presents the 3D geocellular model parameters. This is composed of a single segment reservoir with seven hydraulically connected reservoir units and 187 layers. The reservoir properties were propagated as "conditioned to facies", to consider the facies as the leading parameter in $3 \mathrm{D}$ space. In order to propagate 
Table 2 Reservoir and fluid properties

\begin{tabular}{ll}
\hline Property & Value \\
\hline Datum depth & $4600 \mathrm{ftss}$ \\
Initial reservoir pressure, Pi & $2010 \mathrm{psia}$ \\
Bubble point pressure, Pb & $1998 \mathrm{psia}$ \\
FBHP (06, 16) & $1912 \mathrm{psia}$ \\
Reservoir oil density & $0.61 \mathrm{~g} / \mathrm{cc}$ \\
Reservoir oil viscosity & $0.5 \mathrm{cp}$ \\
Proven oil column & $170 \mathrm{ft}$ \\
Boi @ Pi & $1.636 \mathrm{rb} / \mathrm{stb}$ \\
Initial solution GOR, Rsi & $298 \mathrm{scf} / \mathrm{stb}$ \\
Reservoir temperature & $167^{\circ} \mathrm{F}$ \\
Stock tank oil density & $28.9{ }^{\circ} \mathrm{API}$ \\
Gas gravity (air $=1)$ & 0.89 \\
Rock compressibility & $3.00 \mathrm{E}-06$ \\
Average porosity & $0.28 \mathrm{v} / \mathrm{v}$ \\
Average water saturation, Sw & $0.2 \mathrm{v} / \mathrm{v}$ \\
Average permeability, K & $3100 \mathrm{mD}$ \\
STOIIP & $201.0 \mathrm{MMSTB}$ \\
Np (06/16) & $84.3 \mathrm{MMSTB}$ \\
RF (06/16) & $41.9 \%$ \\
\hline
\end{tabular}

Table 3 3D reservoir model dimensions

\begin{tabular}{llll}
\hline Model dimensions & & & \\
\hline Axis & Min & Max & Delta \\
\hline$X$ & 481,003 & $491,937.8$ & $10,934.82$ \\
$Y$ & $54,392.98$ & $60,340.74$ & 5947.76 \\
Depth & -4670 & -4120 & 550 \\
Cells $(\mathrm{NX} \times \mathrm{NY} \times \mathrm{NZ})$ & $98 \times 46 \times 187$ & & \\
Total number of 3D cells & 842,996 & & \\
Number of faults & 0 & & \\
Number of zones & 7 & & \\
Number of segments & 1 & & \\
\hline
\end{tabular}

the properties measured on cores into the 3D model, the relationship between those properties and the petrophysical properties, i.e. effective porosities (PHIE), shale volume (VSH), and water saturation ( $\mathrm{Sw}$ ), was investigated and properly correlated. This step is necessary as core data are usually very limited compared to log data and the reservoir volume.

A numerical flow simulation was performed by integrating all requisite reservoir and fluid data to demonstrate model reliability for future reservoir management practices. Two model cases were established with only the permeability models (PERM-X, - Y, -Z) as variables to validate the applicability of the proposed methodology for permeability modelling and hydraulic flow unitization. The proposed $\overline{R_{\text {tot }}}$ permeability model and the Timur-Coates

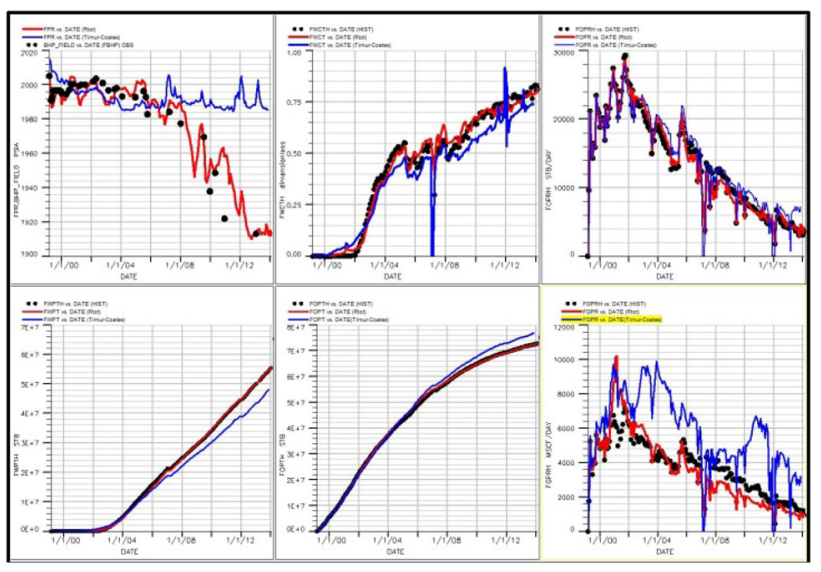

Fig. $153 D$ dynamic simulation results for pressures and saturation match. The black dots, blue lines and red lines represent historical/ measured data, Timur Coates and the proposed $\left(\overline{R_{\text {tot }}}\right)$ results, respectively. The proposed model indicate appreciable match than the Timur Coates model

methods were implemented. Both models were constrained to RESV for material/energy balance (pressure match) and ORAT for saturation match.

Figure 15 presents results from the simulations runs. The black dots, blue curves, and red curves are models responses for observed/historical, Timur-Coates and proposed method, respectively. The results demonstrate the efficacy of the proposed methodology for improved reservoir characterization. Plot 1 of Fig. 15 presents the energy/material balance plot. This indicates that the proposed method calibrates effectively to the static bottomhole pressures compared to the Timur-Coates-based model. The pessimistic Timur-Coates permeability model shows a highly energized system. In all scenarios for pressure and saturation match, the proposed model outperforms the Timur-Coates model.

\section{Conclusions}

1. The modified reservoir quality index methodology using the normalized pore throat radius concept demonstrates improved capabilities for petrophysical evaluation.

2. The cumulative normalized RQI presents potentials for reservoir flow units' definition which bears strong correlation between rock-type-based reservoir zonation and petrophysical-based flow units.

3. The proposed model demonstrates an improved capability in aligning all samples within same genetic reservoir units on same trend/straight line than existing RQI method (Ameafule et al.). This presents an improved hydraulic flow zone delineation method using the RQI concept. 
4. The proposed model possesses the capability of modelling extreme value of connections. This results in improved prediction of permeability and permeability distributions from wireline logs in partially cored/ uncored intervals and adjacent wells for improved completions and enhanced recovery decisions.

5. The proposed method outperforms existing works of Timur-Coates, and NMR-based SDR, and Coates methods. This depicts potentials for efficient reservoir modelling.

Acknowledgements The authors would like to thank the management of the Department of Petroleum Resources (DPR), and the Petroleum Technology Development Fund (PTDF), Nigeria, for their support and permission to publish this article. Special thanks and appreciation to the SPDC petrophysics and geosolution team who were involved in discussions that made this possible and to Schlumberger for their Techlog petrophysical and statistical tool, PETREL and ECLIPSE reservoir simulators tools.

Open Access This article is distributed under the terms of the Creative Commons Attribution 4.0 International License (http:// creativecommons.org/licenses/by/4.0/), which permits unrestricted use, distribution, and reproduction in any medium, provided you give appropriate credit to the original author(s) and the source, provide a link to the Creative Commons license, and indicate if changes were made.

\section{References}

Amaefule JO, Altunbay M, Tiab D, Kersey DG, Keelan DK (1993) Enhanced reservoir description: using core and $\log$ data to identify hydraulic (flow) units and predict permeability in uncored intervals/wells. SPE 26436, presented at 68th annual. Technical conference and exhibition. Houston, TX

Carmen PC (1937) Fluid Flow through Granular Beds. Trans, AIChE 15:150

Kozeny J (1927) Uber Kapillare Leitung des Wassers im Boden, Stizurgsberichte. Royal Academy of Science, Vienna, Proc Class I 136:271

Onuh HM, Ogbe DO, Nwosu C (2015a) Genetic units based permeability prediction for clastic reservoirs using normalized pore throat radius (Niger Delta as case study). Int J Pet Eng IJPE 1(4)

Onuh HM, Arinkoola OA, David OO (2015b) Genetic unit averages of pseudo-normalized pore throat radius for improved permeability predictions (Niger Delta as case study). J Pet Explor Prod Technol 5(2):147-155

Tiab D (2000) Advances in petrophysics, vol 1-flow units. Lecture notes manual, University of Oklahoma 